\title{
ALFABETIZAÇÃO, PROGRESSÃO E AVALIAÇÃO: REFLEXÕES SOBRE AS APRENDIZAGENS DA CRIANÇA
}

\section{LITERACY, PROGRESSION AND EVALUATION: REFLECTIONS ON THE CHILD'S LEARNINGS}

\author{
Magna do Carmo Silva \\ Doutora, Universidade Federal de Pernambuco - UFPE \\ Recife, Pernambuco - Brasil. \\ magna_csc@yahoo.com.br
}

\begin{abstract}
Resumo: O trabalho investiga a relação entre avaliação e progressão das aprendizagens acerca da escrita ao final do ciclo de alfabetização. Para isso, discutimos a relação entre alfabetização, organização escolar e progressão, bem como os conhecimentos necessários à consolidação do processo de alfabetização. Apresentamos, ainda, resultados de uma pesquisa que realizou entrevistas com duas docentes do terceiro ano do ciclo de alfabetização, observações de aulas e atividade de escrita (palavras e textos) com as crianças das duas turmas. Essa pesquisa tinha como objetivo investigar a (des)consideração da relação entre os conhecimentos sobre a escrita, avaliação e progressão no final do ciclo de alfabetização. Os resultados indicam metodologias semelhantes e comprometimento das professoras com a aprendizagem das crianças, pois todas agregaram mais conhecimentos sobre a escrita e a produção textual ao final do ano letivo. Por fim, problematizamos os encaminhamentos das escolas com base nas aprendizagens das crianças ao final desse período.
\end{abstract}

Palavras-Chave: Aprendizagem. Avaliação. Ciclo. Escrita. Progressão.

Abstract: The work investigates the relationship between evaluation and progression of the learnings concerning the writing at the end of the literacy cycle. For that, we discussed the relationship among literacy, school organization and progression as well as the necessary knowledge to the consolidation of the literacy process. We presented, still, results of a research that accomplished interviews with two educational of the third year of the literacy cycle, observations of classes and writing (words and texts) activity with the children of the two groups. This research had as objective investigates the consideration (give) of the relationship among the knowledge on the writing, evaluation and progression in the end of the literacy cycle. The results indicate similar methodologies and the teachers' compromising with the children's learning, because all joined more knowledge about the writing and the textual production at the end of the school year. Finally, we problematized the directions of the schools with base in the learnings of the children at the end of that period.

Keywords: Learning. Evaluation. Cycle. Writing. Progression.

\section{Para citar - (ABNT NBR 6023:2018)}

SILVA, Magna do Carmo. Alfabetização, progressão e avaliação: reflexões sobre as aprendizagens da criança. Eccos - Revista Cientifica, São Paulo, n. 55, p. 1-18, e8828, out./dez. 2020. Disponível em: https://doi.org/10.5585/eccos.n55.8828. 


\section{Introdução}

No Brasil, em 4 de julho de 2012, a Portaria no 867 instituiu o Pacto Nacional pela Alfabetização na Idade Certa (PNAIC), que, dentre outras ações, propôs a organização do ciclo de alfabetização com duração de três anos. Essa forma de organização escolar visava possibilitar que até o final do terceiro ano do Ensino Fundamental (EF), todas as crianças estivessem alfabetizadas. Dois anos depois, com base no Plano Nacional de Educação (PNE) (BRASIL, 2014), intensificou-se a definição e implementação de políticas públicas para a alfabetização, a exemplo da Política Nacional de Avaliação da Alfabetização (ALAVARSE, 2013), que se configura, atualmente, por avaliações internas (realizadas pelos professores nas suas salas), e avaliações externas às escolas (municipais, estaduais e nacionais).

Com a constituição do ciclo de alfabetização pretende-se que as crianças, ao longo dos três anos iniciais do EF, consolidem esse processo por meio da continuidade e do aprofundamento das aprendizagens. Esse período é considerado como um ciclo sequencial de ensino no qual a avaliação deve ter um caráter processual, participativo, formativo, acumulativo, diagnóstico e redimensionador da ação pedagógica. Consideramos essa progressão em três dimensões: "progressão escolar", relacionada ao direito que a criança tem de avançar na escolarização; "progressão do ensino", definição do que se propõe para os três anos iniciais do EF quanto à Língua Portuguesa; e "progressão das aprendizagens", quando esse avanço está diretamente ligado à qualidade crescente das aprendizagens construídas.

A Pesquisa de Cruz (2008) aponta para um descompasso entre essas progressões, uma vez que se observou, no final do terceiro ano do EF, algumas crianças alfabetizadas e outras em processo inicial de alfabetização. Isto revela que muitas avançam no ano escolar sem necessariamente progredirem nas aprendizagens. Este dado também foi encontrado na pesquisa de Booke (2008). Os resultados da Avaliação Nacional da Alfabetização (ANA), divulgados em 2015, corroboram as pesquisas citadas, pois indicam que uma em cada cinco crianças só desenvolveu a capacidade de ler palavras isoladas, e poucas atingiram os maiores níveis de proficiência na leitura e na escrita ao final do $3^{\circ}$ ano (INSTITUTO NACIONAL DE ESTUDOS E PESQUISAS ANÍSIO TEIXEIRA, 2015a, 2015b).

Com base nesse contexto, este artigo se propõe a investigar a relação entre a avaliação e a progressão das aprendizagens acerca da escrita ao final do ciclo de alfabetização. Inicialmente, discutiremos sobre a relação entre alfabetização, organização escolar, avaliação e progressão; em seguida, refletiremos sobre os conhecimentos necessários à consolidação do processo de alfabetização; e, por fim, apontaremos resultados de uma pesquisa de campo que 
investigou como é tratada na escola a relação entre conhecimentos sobre a escrita, avaliação e progressão no final do ciclo de alfabetização.

\section{Organização escolar, alfabetização e avaliação: relações entre a progressão escolar e da aprendizagem}

De acordo com pesquisas sobre a história da organização escolar no Brasil (FARIA FILHO; VIDAL, 2000), a seriação instalou-se por meio dos grupos escolares que tinham o objetivo de ensinar a ler e escrever por meio da homogeneização dos conteúdos, métodos, tempos e espaços de aprendizagem. Em décadas posteriores (1970, 1980 e 1990), o acesso à escola pública foi ampliado às camadas populares, e a dinâmica interna da escola seriada passou a ser estudada como uma das promotoras de fracasso escolar.

No estudo das práticas de alfabetização na escola seriada, Mortatti (2000) aponta que os métodos tradicionais de alfabetização eram de dois tipos fundamentais: sintéticos e analíticos. Apesar das diferenças entre eles, ambos consideravam a escrita como um código a ser transmitido e memorizado, e não um sistema de representação com princípios que precisam ser compreendidos. Nesse contexto, as crianças na fase de alfabetização realizavam testes de leitura para identificar a sua prontidão. Assim, o processo de alfabetização ocorria em duas etapas: uma etapa preparatória e a outra de alfabetização propriamente dita. Os testes tinham como objetivo medir o grau de maturidade das crianças necessário à aprendizagem da leitura e da escrita, e classificá-las para a organização homogênea das classes. $\mathrm{O}$ fracasso era considerado como indicação da incapacidade dessas crianças de aprenderem a ler e escrever.

$\mathrm{Na}$ tentativa de encontrar soluções para o fracasso escolar na alfabetização, o Ciclo Básico de Alfabetização (CBA) surgiu, na década de 1980, como possibilidade de eliminação da reprovação no final da $1^{\mathrm{a}}$ série do $1^{\mathrm{o}}$ grau, ampliando o período de alfabetização para dois anos, assegurando a continuidade do processo (MAINARDES, 2009). Segundo Mainardes (2009), o processo de formação da política de ciclos no Brasil pode ser dividido em três períodos: o primeiro, entre 1918/1921 e 1984, marcado pela crítica à reprovação e discussões em torno da promoção automática; o segundo, entre 1984 e 1990, formado com a emergência do ciclo básico de alfabetização; e o terceiro período, a partir dos anos de 1990, formado a partir da ampliação do sistema em ciclos para todo o EF por algumas redes municipais.

Com base na revisão de dissertações e teses sobre ciclos, Mainardes (2009) indica certo distanciamento entre o que é posto nas propostas oficiais, voltadas para os ciclos, e o que efetivamente era praticado no interior das escolas. Ou seja, supõe-se que a escola em ciclos possa estar camuflando a falta de progressão da aprendizagem com a falsa progressão escolar, 
configurando-se essa progressão escolar como uma "exclusão branda" (FREITAS, 2003). As pesquisas de Linch (2002), por exemplo, identificaram situações de "exclusão escolar oculta", nas quais crianças eram promovidas, mas permaneciam excluídas dentro das salas de aula, sem receber o apoio necessário para progredirem em suas aprendizagens.

Para romper com a seriação faz-se necessário reconhecer que essa forma de organização escolar está pautada nas "práticas de submissão" cuja "lógica de exclusão se completa com a lógica da submissão" (FREITAS, 2003, p. 37). Nesse sentido, para o ciclo ser transformador ele deve "[...] mais do que uma unidade do tempo escolar, constituir-se em uma medida intermediária para confrontar a escola dentro de uma nova lógica, cujas concepções [...] entram em conflito com a lógica seriada" (FERNANDES, 2009, p. 117-118). Porém, por um lado, o regime em ciclos por si só não garante a aprendizagem da criança e, por outro lado, a progressão escolar não resolve o problema da não aprendizagem.

Em 2012 foi instituído nacionalmente o ciclo de alfabetização (três anos sem reprovação entre eles) para os três anos iniciais do EF, conforme já explicitado na introdução deste artigo. Concordamos com Cortella (2005, p. 49) ao enfatizar que "a finalidade dos ciclos é dificultar a reprovação burra, aquela que acontece por falha da nossa organização ou da nossa estrutura", como historicamente ocorreu na escola organizada em série.

Portanto, ao falarmos em ciclos é importante discutir as práticas de avaliação dos professores que já estão cristalizadas e que precisariam ser redimensionadas. Mainardes (2009) aponta que a transposição das séries para os ciclos implicaria uma mudança de "código", ou seja, uma mudança da lógica de funcionamento da política educacional, da gestão escolar, da perspectiva de avaliação, da dinâmica na sala de aula e da participação da criança. Este processo precisaria envolver professores, crianças, pais, coordenadores, gestores em uma perspectiva formativa-regulativa, viabilizando feedback e reorientação de posturas nas práticas pedagógicas a fim de regular e adequar essas práticas às necessidades das crianças (SILVA, 2004).

\section{Consolidação do processo de alfabetização e as práticas de ensino}

Em relação à construção do conhecimento sobre a escrita alfabética, na perspectiva da psicogênese da escrita (FERREIRO; TEBEROSKY, 1999), esse processo se dá de forma ativa, por meio da elaboração de hipóteses relacionadas a duas perguntas básicas: o "que" a escrita representa (nota) e "como" ela faz essa representação (notação). A criança em processo de alfabetização compreende, portanto, que a escrita alfabética representa/nota a pauta sonora das 
palavras e que essa representação/notação é feita considerando segmentos menores que as sílabas (os fonemas). Até atingirem esse nível de compreensão que caracteriza a escrita alfabética, as referidas autoras perceberam que alunos em processo de alfabetização vivenciavam outras hipóteses de escrita (escrita "pré-silábica”, em que não há correspondência grafo-fônica, e escrita "silábica", em que já há essa correspondência, mas no nível da sílaba).

No entanto, atingir a hipótese alfabética da escrita não significa estar alfabetizado, uma vez que é preciso que a criança reflita sobre a norma ortográfica, compreendendo as regularidades e as irregularidades relacionadas às correspondências grafo-fônicas (MORAIS, 1999). Como implicações pedagógicas dessa reflexão salientamos a importância de pensarmos na progressão das aprendizagens relacionadas à apropriação da escrita alfabética e da norma ortográfica.

Nessa perspectiva, outra discussão importante ao tratarmos da consolidação do processo de alfabetização relaciona-se à necessidade do ler e escrever textos diversos com autonomia em diferentes situações cotidianas. Ou seja, seria a relação entre alfabetização e letramento, pois a simples mudança de paradigma na alfabetização não causou melhoria evidente nas práticas de alfabetização (SOARES, 2016). Nesse sentido, a referida autora destaca que a alfabetização vem sendo obscurecida pelo letramento, perdendo sua especificidade no contexto brasileiro. Agregado a isto, aponta que os ciclos implantados no país não trouxeram metas para a alfabetização nos anos do ciclo, e isto pode ter prejudicado as crianças. Conforme a autora, seria necessário assumir a especificidade de ambos os processos, sabendo que eles são indissociáveis, "reinventando" a "alfabetização", no sentido de desenvolver em salas de alfabetização o duplo objetivo de alfabetizar e letrar (ou alfabetizar letrando).

Segundo Soares (2016), é importante considerar o ensino explícito e sistemático do sistema de escrita alfabético e suas convenções ao mesmo tempo em que é preciso adotar práticas de leitura e escrita de textos de diferentes gêneros com as crianças, mesmo em fase inicial de alfabetização. Cabe, portanto, ao professor ter ações pedagógicas diferenciadas e planejadas. Assim, para que a criança construa conhecimentos sobre a escrita e tenha o seu processo de alfabetização consolidado, o docente necessita compreender os princípios e teorias subjacentes a esse processo e criar procedimentos diferenciados que promovam a aprendizagem e ajustes adequados à progressão dessas aprendizagens ao mesmo tempo em que identificam as dificuldades.

$\mathrm{Na}$ análise das práticas de alfabetização é importante perceber que os professores constroem as suas práticas no ciclo de alfabetização. Nesse sentido, Chartier (2007) anunciou que o professor de alfabetização constrói suas práticas baseando-se, entre outros aspectos, no 
que está sendo discutido no meio acadêmico e transposto para os textos do saber; nesse processo, a partir de suas reinterpretações, o docente considera o que é possível e pertinente ser feito em sala de aula. As mudanças didáticas e pedagógicas resultam na construção de 'dispositivos' táticos à medida que o docente enfrenta situações de conflito ou de exercício da maestria de sua profissão. Nesse contexto, entendemos que as práticas de alfabetização dos professores no ciclo de alfabetização são constituídas de procedimentos rotineiros e inovadores: o "saber fazer" dos professores. Na articulação desses elementos ocorre a possibilidade de fabricações e reconstruções dessas práticas.

\section{A (des)consideração da relação entre os conhecimentos sobre a escrita e sua relação com a avaliação e progressão}

Nesta seção apresentamos um relato de pesquisa que investigou a (des)consideração da relação entre os conhecimentos sobre a escrita, avaliação e progressão no final do ciclo de alfabetização. Participaram da pesquisa professores e alunos de duas turmas do $3^{\circ}$ ano do EF pertencentes a escolas de dois municípios de Pernambuco, Brasil. A escolha das redes municipais deveu-se ao fato de elas serem organizadas de forma diferente quanto à estrutura escolar e, ainda assim, possuírem um avanço quanto aos índices de leitura nas avaliações nacionais (INSTITUTO NACIONAL DE ESTUDOS E PESQUISAS ANÍSIO TEIXEIRA, 2015a, 2015b).

A escola nomeada por nós como Escola C pertencia a uma rede de ensino organizada em ciclos, com os três primeiros anos do EF dedicados ao ciclo de alfabetização. A outra escola, Escola $S$, pertencia a uma rede de ensino com organização escolar em séries, que apresentava a possibilidade de reprovação, na época da coleta de dados da pesquisa, a partir do $2^{\circ}$ ano. Ambas estavam localizadas em bairros populares e tinham uma estrutura simples pela quantidade de salas e espaço físico.

A turma da Professora C (da Escola Ciclada) era formada por 20 crianças, e a da Professora S (da Escola Seriada) era composta por 27 crianças. Dentre as 20 crianças da escola ciclada, três já haviam sido retidas no ano anterior e 17 eram provenientes do $2^{\circ}$ ano da própria escola. Já na escola seriada, das 27 crianças matriculadas no $3^{\circ}$ ano, três tinham sido retidas no $3^{\circ}$ ano (duas dessas eram repetentes pela segunda vez) e 24 eram provenientes do $2^{\circ}$ ano da própria escola. As duas professoras eram formadas em Pedagogia e tinham mais de 10 anos de formadas.

Utilizamos três procedimentos metodológicos: (1) realização de atividade escrita (doze palavras e relato de experiência) com as crianças das duas turmas, no início e final de ano letivo; 
(2) entrevistas com as professoras; (3) observações de 15 aulas das professoras. Os dados das atividades com as crianças foram analisados tanto qualitativamente quanto quantitativamente, e as categorias elaboradas serão apresentadas na seção 3.2. As categorias de análise das observações tinham como foco: atividades de análise linguística e atividades de produção textual. Em todas as atividades foi observada a forma como a professora organizava os alunos na sala e como intervinha em cada uma delas. $\mathrm{Na}$ análise utilizamos as técnicas metodológicas da Análise de Conteúdos (BARDIN, 2007) e, posteriormente, a triangulação dos dados obtidos. Os resultados serão apresentados a seguir.

\subsection{As práticas de alfabetização e letramento no último ano do ciclo de alfabetização}

$\mathrm{Na}$ análise das práticas de alfabetização identificamos duas categorias: a exploração dos eixos da língua portuguesa e a organização das práticas de alfabetização.

Em relação à "exploração dos eixos da língua portuguesa"1, verificamos que na maior parte dos dias observados, nas duas salas, as crianças vivenciaram atividades de exploração da leitura e análise linguística, e, com menor frequência, atividades de produção textual.

Em relação às atividades de leitura, ambas as professoras realizaram todos os dias leituras de poemas, tirinhas, histórias, músicas, fábulas, dentre outros gêneros. Durante a maior parte dessas atividades a Professora $\mathrm{C}$ era a leitora da turma, provavelmente pelo fato de a maioria de suas crianças ainda estarem em processo inicial de apropriação do Sistema de Escrita Alfabética (SNA). A Professora C promoveu, durante os momentos de leitura, um trabalho de reconhecimento global das palavras por meio de atividades diferenciadas com o grupo de crianças que ainda não tinha se apropriado do SNA. Em relação ao $3^{\circ}$ ano $S$, várias modalidades de leitura foram vivenciadas pelas crianças: em voz alta, em dupla e silenciosamente. Além disso, a gestora da Escola $\mathrm{S}$ contribuía com o processo de alfabetização e letramento das crianças, incentivando-as a interagir de forma prazerosa com a leitura e a escrita por meio de textos que estavam espalhados no pátio da escola.

Em relação ao eixo da análise linguística, a professora $\mathrm{C}$, apesar de estar em uma turma com $80 \%$ das crianças alfabéticas no início do ano, desenvolveu um razoável número de atividades (40\%) que visavam à apropriação da escrita e à reflexão fonológica com a finalidade de atender àqueles que ainda não tinham se alfabetizado. Já na turma do $3^{\circ}$ ano $\mathrm{S}$ não foram feitos grandes investimentos nessas atividades, apesar de ela também apresentar no perfil inicial

\footnotetext{
${ }^{1}$ Consideramos o eixo da leitura na análise dos dados pelo fato de, durante esses momentos, as professoras realizarem muitas intervenções e atividades de análise linguística com as turmas.
} 
algumas crianças em hipóteses iniciais de escrita. Além disso, a análise das práticas das professoras indicou que ambas exploraram a norma ortográfica, o uso do plural e singular, o aumentativo e diminutivo, a formação das frases, entre outros aspectos.

Em relação à exploração do eixo da produção textual, as turmas apresentaram variedade de gêneros contemplados. Apenas em alguns desses momentos as professoras apresentaram a finalidade e os destinatários dos textos e exploraram algumas características dos gêneros, orientando a sua produção e revisão com intervenções diversificadas. Nas entrevistas elas apontaram que possuíam certa dificuldade na condução das atividades de produção textual e não tinham domínio dos comandos a serem dados quanto ao planejamento, à escrita e à revisão dos textos.

Em relação à "organização das práticas de alfabetização", observamos que as professoras estabeleciam uma rotina como elemento estruturante da prática pedagógica.

Segundo elas, a organização diária das atividades possibilitava o trabalho com todos os eixos de ensino da língua portuguesa, a organização das sequências de atividades a serem desenvolvidas, além de informar às crianças o que iria ser explorado e os tipos de atividades que iriam vivenciar, favorecendo a participação. Para isso, ambas as professoras organizaram um horário no começo do ano que indicava como as áreas do conhecimento poderiam ser trabalhadas semanalmente. A área de língua portuguesa deveria ser trabalhada três vezes por semana por meio da utilização de recursos diversificados.

Durante as atividades de língua portuguesa a professora $\mathrm{C}$ desenvolveu atividades adequadas e desafiadoras à capacidade de compreensão das crianças em relação à escrita alfabética. Para isso, dividia a turma entre as que estavam nas categorias iniciais de apropriação da escrita alfabética (Grupo A) e os alfabéticos (Grupo B). Na segunda-feira era explorada a gramática com as crianças do Grupo B, enquanto as demais faziam atividades diversificadas direcionadas à apropriação da escrita alfabética e reflexão fonológica. Na quarta-feira a turma se dividia: o Grupo B se dirigia para a aula de informática, enquanto o Grupo A ficava em sala e trabalhava de forma variada atividades de leitura e produção de textos; depois trocavam de sala e ela trabalhava com o grupo B dando um maior aprofundamento aos eixos da leitura e produção de textos. Na sexta-feira ela explorava uma atividade no livro didático, buscando responder coletivamente às questões e estimulando para que todos participassem. Essa professora também passou atividades diferenciadas para casa em vários dias para os dois grupos de crianças.

A Professora S realizava sempre a leitura de um texto literário no início da aula e, em seguida, propunha uma atividade relacionada a ele na qual explorava aspectos da análise 
linguística, tais como: formação de palavras, análise de silabas, consciência fonológica, dentre outras. Na maior parte das atividades propostas ela conduzia coletivamente a turma sem dar um atendimento específico às crianças em fase de alfabetização. Apesar disso, ela promovia situações de troca de conhecimentos entre as crianças durante as atividades em grupo.

As professoras relataram, na entrevista, que tinham dificuldade em atender à heterogeneidade de conhecimentos das crianças sobre a produção de palavras e textos no $3^{\circ}$ ano do ciclo de alfabetização. Em certa medida todas buscavam fabricar práticas de alfabetizar letrando, pelo conjunto das atividades observadas. Apesar disso, se por um lado identificamos uma busca por garantir a alfabetização inicial, por outro, a continuidade do processo de consolidação desta ficou comprometida. Provavelmente, a ausência de aprofundamento nas práticas de ensino da leitura e da produção textual, somada a outros fatores, contribuiu para que as crianças das turmas não apresentassem diferença significativa na maioria das categorias analisadas quanto à produção textual, apesar de todas estarem alfabéticas no perfil final.

\subsection{Progressão das aprendizagens sobre a escrita no último ano do ciclo de alfabetização}

Para analisar as escritas das palavras pelas crianças, elaboramos, com base nas pesquisas de Ferreiro e Teberosky (1999) e de Morais (1999), "três categorias e cinco subcategorias"2. Apresentaremos a seguir, de forma sucinta, essa categorização:

$\checkmark$ Escrita Pré-Silábica: não há compreensão de que existe relação entre escrita e pauta sonora.

$\checkmark$ Escrita Silábico-Alfabética: a criança começa a perceber que as sílabas têm mais de uma letra, mas não tem consistência ainda para a marcação de todos os fonemas, e, muitas vezes, não utiliza os grafemas adequados.

$\checkmark$ Escrita Alfabética: a criança compreende que as sílabas são compostas por unidades menores (os fonemas). Essa categoria se subdivide em:

$\checkmark$ Alfabético I: alfabético com pouco domínio das correspondências grafo-fônicas diretas;

$\checkmark$ Alfabético II: alfabético com pouco domínio das regularidades contextuais; Alfabético III: alfabético com razoável domínio das regularidades contextuais;

\footnotetext{
${ }^{2}$ Optamos por usar as categorias de Ferreiro e Teberosky (1999), e de Morais (1999), pelo fato de ainda termos alunos no $3^{\circ}$ ano na fase inicial de compreensão da escrita alfabética, e alunos que já escreviam ortograficamente no início do ano letivo. Desta forma, pudemos analisar todas as respostas dadas pelas crianças às atividades propostas na pesquisa. A categoria silábica de Ferreiro e Teberosky (1999) não foi usada pelo fato de não termos identificado crianças nessa fase de compreensão da escrita.
} 
Alfabético IV: alfabético com bom domínio das regularidades contextuais; e Alfabético V: alfabético com escrita convencional.

A Tabela 1 apresenta o desempenho das crianças nas atividades de escrita de palavras.

Tabela 1 - Progressão das aprendizagens das crianças na escrita de palavras

\begin{tabular}{|c|c|c|c|c|c|c|c|c|}
\hline \multirow{3}{*}{$\begin{array}{l}\text { Subcategoria atende } \\
\text { plenamente }\end{array}$} & \multicolumn{4}{|c|}{$3^{\circ}$ ano $\mathrm{C}$} & \multicolumn{4}{|c|}{$3^{\circ}$ ano $S$} \\
\hline & \multicolumn{2}{|c|}{ Perfil Inicial } & \multicolumn{2}{|c|}{ Perfil Inicial } & \multicolumn{2}{|c|}{ Perfil Inicial } & \multicolumn{2}{|c|}{ Perfil Inicial } \\
\hline & $\%$ & Qt. & $\%$ & Qt. & $\%$ & Qt. & $\%$ & Qt. \\
\hline Pré-Silábico (PS) & 10,0 & 02 & - & - & - & - & - & \\
\hline Silábico-Alfabético (AS) & 10,0 & 02 & - & - & 11,2 & 03 & - & \\
\hline Alfabético I (AI) & 15,0 & 03 & $\mathbf{5 , 0}$ & 01 & - & - & - & \\
\hline Alfabético II (AII) & - & - & 10,0 & 02 & 14,8 & 04 & 11,2 & 03 \\
\hline Alfabético III (AIII) & 20,0 & 04 & 10,0 & 02 & 14,8 & 04 & 11,2 & 03 \\
\hline Alfabético IV (AIV) & 15,0 & 03 & 15,0 & 03 & 29,6 & 08 & 7,2 & 02 \\
\hline Alfabético V (AV) & 30,0 & 06 & 60,0 & 12 & 29,6 & 08 & 70,4 & 19 \\
\hline Total & 100,0 & 20 & 100,0 & 20 & 100,0 & 27 & 100,0 & 27 \\
\hline
\end{tabular}

Fonte: Elaboração da autora.

A análise da Tabela 1 indica que grande parte das duas turmas já era alfabética no início do ano letivo (16 crianças na Escola C e 24 crianças na Escola $S$ ), provavelmente pelo trabalho realizado nos $1^{\circ}$ e $2^{\circ}$ anos com foco na apropriação da escrita alfabética, conforme relato das professoras nas entrevistas. Além disso, o perfil de saída do $2^{\circ}$ ano na Escola $S$, presente na proposta curricular da rede de ensino orientava que as crianças desse ano terminassem o ano letivo no nível "alfabético, podendo realizar troca de letras". O documento ainda afirmava que, caso não atingissem esse patamar, as crianças deveriam ser retidas. Este fato pode ter elevado o índice de crianças alfabéticas no perfil inicial do $3^{\circ}$ ano S. Apesar disso, ainda encontramos no perfil inicial dos terceiros anos uma parcela das crianças em níveis iniciais de apropriação da escrita, tais como: pré-silábicos (duas no $3^{\circ}$ ano C), e silábicos alfabéticos (três no $3^{\circ}$ ano $\mathrm{S}$ e duas no $3^{\circ}$ ano $\left.\mathrm{C}\right)$.

No perfil final todas as crianças das duas turmas terminaram o ano na hipótese alfabética, com variados níveis de apropriação da norma ortográfica, e todas as crianças apresentaram progressão em relação à aprendizagem da escrita alfabética e da norma ortográfica. Apesar disso, as crianças das duas escolas que estavam, no perfil final, na categoria Alfabética I e II foram retidas por não terem ainda autonomia em produção textual.

Outra atividade aplicada às crianças foi a de produção textual. Para desenvolver essa atividade solicitamos às crianças a produção de dois relatos de experiência que tinham como finalidade escrever, no perfil inicial, sobre algum passeio que a criança fez com sua família, amigos ou professores, e no perfil final, sobre algumas atividades que vivenciaram na escola 
durante aquele ano e que gostariam de relatar para o pesquisador. Inicialmente, esses textos foram separados como ilegíveis (não apresentavam palavras legíveis); com baixa legibilidade (apresentavam palavras legíveis e ilegíveis); e legíveis (todas as palavras eram legíveis), sendo considerados para análise apenas os textos legíveis.

Dos textos produzidos pelas duas turmas, no $3^{\circ}$ ano $\mathrm{C}$ eram legíveis apenas $65 \%$ (perfil inicial); e $85 \%$ (perfil final); e no $3^{\circ}$ ano $\mathrm{S}, 81,5 \%$ (perfil inicial); e 92,6\% (perfil final) dos textos. $\mathrm{O}$ avanço das duas turmas quanto à legibilidade dos textos entre os perfis representa um resultado significativo para esse ano escolar, tendo como foco as discussões que vimos traçando sobre a necessidade de alfabetizar letrando. Os textos legíveis, tanto no perfil inicial como no perfil final, foram organizados em seis categorias. Para definição das categorias levamos em conta os aspectos gráficos e os relacionados à textualidade.

As categorias relacionadas à grafia tratam da (o):

$\checkmark$ Segmentação correta entre as palavras: o texto apresenta as palavras com espaçamento adequado entre elas.

$\checkmark$ Uso da escrita ortográfica: o texto apresenta o uso adequado da norma ortográfica relativa às regras diretas e contextuais na escrita de palavras.

As categorias relacionadas à textualidade tratam dos aspectos da:

$\checkmark$ Adequação aos comandos: propósitos de situação de escrita, finalidade, destinatário e temática solicitada. $O$ texto relata uma situação vivenciada de acordo com o comando.

$\checkmark$ Utilização de conhecimento sobre o gênero: o texto caracteriza-se como um relato de experiência e contém uma linguagem simples, escrito na $1^{\mathrm{a}}$ pessoa do singular e/ou plural, apresenta certa expressividade por meio de algumas marcas textuais de autoria e/ou diálogo e/ou tempo.

$\checkmark$ Coesão: o texto apresenta um pensamento contínuo da criança em uma progressão de fatos vividos, sem apresentar meramente frases justapostas; usa conectivos adequados para manter a articulação entre as partes.

$\checkmark$ Estruturação dos períodos e da concordância entre as palavras no texto: o texto apresenta completude dos períodos e concordância entre as palavras que o compõem.

Para cada categoria relacionada à grafia dos textos e à textualidade, agrupamos os textos em três subcategorias: Não Atende, Atende Parcialmente, e Atende Plenamente. A Tabela 2 
apresenta os resultados da análise dos textos que atendiam plenamente aos aspectos analisados na produção textual.

Tabela 2 - Percentual de textos na subcategoria "Atende plenamente"

\begin{tabular}{|c|c|c|c|c|c|c|c|c|}
\hline \multirow{3}{*}{$\begin{array}{l}\text { Subcategoria atende } \\
\text { plenamente }\end{array}$} & \multicolumn{4}{|c|}{$3^{\circ}$ ano C } & \multicolumn{4}{|c|}{$3^{\circ}$ ano $S$} \\
\hline & \multicolumn{2}{|c|}{ Perfil Inicial } & \multicolumn{2}{|c|}{ Perfil Inicial } & \multicolumn{2}{|c|}{ Perfil Inicial } & \multicolumn{2}{|c|}{ Perfil Inicial } \\
\hline & $\%$ & Qt. & $\%$ & $\%$ & $\%$ & Qt. & $\%$ & Qt. \\
\hline Segmentação correta & 45,0 & 09 & 75,0 & 15 & 55,6 & 15 & 77,5 & 20 \\
\hline Correcãão ortográfica & 45,0 & 09 & 70,0 & 14 & 51,9 & 14 & 63,3 & 17 \\
\hline Adequação ao comando & 60,0 & 12 & 80,0 & 16 & 51,9 & 14 & 77,5 & 20 \\
\hline $\begin{array}{l}\text { Gênero relato de } \\
\text { experiências }\end{array}$ & 40,0 & 08 & 75,0 & 15 & 22,3 & 06 & 55,9 & 15 \\
\hline Coesão & 20,0 & 04 & 40,0 & 08 & 7,4 & 02 & 40,8 & 11 \\
\hline $\begin{array}{l}\text { Concordância e estrutura } \\
\text { adequada }\end{array}$ & 25,0 & 05 & 55,0 & 11 & 37,0 & 10 & 55,6 & 15 \\
\hline
\end{tabular}

Fonte: Elaboração da autora.

A análise dos resultados relacionados à produção textual indicou que no PI, em relação ao aspecto gráfico dos textos, cerca de metade das duas turmas já produzia textos que atendiam às normas ortográficas, bem como estavam adequadamente segmentados. Em relação aos aspectos da textualidade, ambas as turmas apresentavam dificuldades em relação à coesão, estruturação dos períodos e concordância das palavras.

Na comparação entre o perfil inicial e o perfil final, em relação à "produção de textos", não foi encontrada diferença significativa, principalmente pelo fato de as turmas não terem apresentado no perfil final bons índices como esperado para esse ano escolar, tanto relacionado à grafia quanto à textualidade. Este dado indica que, em geral, a consolidação da alfabetização pode ter sido precária no que se refere à autonomia de produzir textos com coesão e coerência após a apropriação da escrita alfabética. Além disso, percebemos que algumas crianças que estavam em fase inicial de alfabetização no perfil inicial apresentaram textos legíveis no final do ano letivo, apesar de terem algumas dificuldades quanto à grafia e à textualidade.

\subsection{A Progressão escolar no final do ciclo de alfabetização}

Destacamos que o período de três anos para alfabetizar sem retenção, na Escola C, possibilitou que todas as crianças do $3^{\circ}$ ano $\mathrm{C}$ avançassem ao longo do ciclo de alfabetização, e os que estivessem com mais dificuldade na compreensão do SNA viessem a se apropriar da escrita, mesmo que no último ano, sem que tivessem sofrido retenção no percurso. Na Escola $\mathrm{S}$, apesar de haver a possibilidade de retenção no final do $2^{\circ}$ ano, havia um sistema de "aprovação com ressalva" que permitia o avanço das crianças que não tinham atingido as competências estabelecidas para o final do referido ano, desde que apresentassem potencial 
para atingi-las no primeiro semestre do $3^{\circ}$ ano. Por isso, presenciamos no perfil inicial do $3^{\circ}$ ano $\mathrm{S}$ algumas crianças com hipóteses silábico-alfabéticas. Essa diversidade no perfil inicial das turmas quanto às aprendizagens sobre a escrita foi apontada por ambas as professoras como um dos elementos que dificultavam a prática de ensino da leitura e da escrita. Os Quadros 1 e 2 indicam os Perfis Iniciais (PI) e os Perfis Finais (PF) das crianças em cada momento avaliado.

Quadro 1 - $3^{\circ}$ ano da Escola C

\begin{tabular}{|c|c|c|}
\hline Criança & PI & PF \\
\hline $3 \mathrm{C} 1^{3}$ & A3 & A5 \\
\hline $3 \mathrm{C} 2$ & A5 & A5 \\
\hline $3 \mathrm{C} 3$ & SA & $\mathrm{A} 4$ \\
\hline $3 \mathrm{C} 4$ & A1 & A2 \\
\hline $3 \mathrm{C} 5$ & A1 & A4 \\
\hline $3 \mathrm{C} 6$ & A5 & A5 \\
\hline $3 \mathrm{C} 7$ & A3 & A5 \\
\hline $3 \mathrm{C} 8$ & SA & $\mathbf{A 2}$ \\
\hline $3 \mathrm{C} 9$ & P2 & A1 \\
\hline $3 \mathrm{C} 10$ & A4 & A5 \\
\hline $3 \mathrm{C} 11$ & A3 & A5 \\
\hline $3 \mathrm{C} 12$ & A5 & A5 \\
\hline $3 \mathrm{C} 13$ & A5 & A5 \\
\hline $3 \mathrm{C} 14$ & A4 & A5 \\
\hline $3 \mathrm{C} 15$ & A5 & A5 \\
\hline $3 \mathrm{C} 16$ & A1 & A4 \\
\hline $3 \mathrm{C} 17$ & P2 & A2 \\
\hline $3 \mathrm{C} 18$ & A5 & A5 \\
\hline $3 \mathrm{C} 19$ & A4 & A5 \\
\hline $3 \mathrm{C} 20$ & A3 & A5 \\
\hline
\end{tabular}

Fonte: Elaboração da autora.

\begin{tabular}{|c|c|c|}
\hline Criança & PI & PF \\
\hline $3 \mathrm{~S} 1$ & A5 & A5 \\
\hline $3 \mathrm{~S} 2$ & A4 & A5 \\
\hline $3 \mathrm{~S} 3$ & A3 & $\mathrm{A} 5$ \\
\hline $3 \mathrm{~S} 4$ & A2 & A5 \\
\hline $3 \mathrm{~S} 5$ & A5 & A5 \\
\hline $3 \mathrm{~S} 6$ & SA & $\overline{\mathrm{A} 2}$ \\
\hline $3 \mathrm{~S} 7$ & A2 & $\mathrm{A} 4$ \\
\hline $3 \mathrm{~S} 8$ & A5 & A5 \\
\hline $3 \mathrm{~S} 9$ & A3 & A5 \\
\hline $3 \mathrm{~S} 10$ & SA & $\mathrm{A} 3$ \\
\hline $3 \mathrm{~S} 11$ & $\mathrm{~A} 4$ & A5 \\
\hline $3 \mathrm{~S} 12$ & A3 & $\mathrm{A} 3$ \\
\hline $3 \mathrm{~S} 13$ & A1 & $\overline{A 2}$ \\
\hline $3 \mathrm{~S} 14$ & A4 & A5 \\
\hline $3 \mathrm{~S} 15$ & A4 & A5 \\
\hline $3 \mathrm{~S} 16$ & A5 & A5 \\
\hline $3 \mathrm{~S} 17$ & A5 & A5 \\
\hline $3 \mathrm{~S} 18$ & $\mathrm{~A} 3$ & $\mathrm{~A} 3$ \\
\hline $3 \mathrm{~S} 19$ & SA & $\overline{A 2}$ \\
\hline $3 \mathrm{~S} 20$ & A4 & A5 \\
\hline $3 \mathrm{~S} 21$ & A4 & A5 \\
\hline $3 \mathrm{~S} 22$ & A2 & A4 \\
\hline $3 \mathrm{~S} 23$ & A5 & A5 \\
\hline $3 \mathrm{~S} 24$ & A4 & A5 \\
\hline $3 \mathrm{~S} 25$ & A5 & A5 \\
\hline $3 \mathrm{~S} 26$ & A5 & A5 \\
\hline $3 \mathrm{~S} 27$ & A4 & A5 \\
\hline
\end{tabular}

Fonte: Elaboração da autora.

Em relação à Escola $\mathrm{C}$, no perfil inicial as três crianças que já tinham sido retidas (conforme explicitado anteriormente) estavam em níveis elementares de apropriação da escrita alfabética e na produção de palavras e de textos $(3 \mathrm{C} 8,3 \mathrm{C} 9,3 \mathrm{C} 17)$. No final do ano letivo, quatro crianças nessa turma foram retidas $(3 \mathrm{C} 4,3 \mathrm{C} 8,3 \mathrm{C} 9$ e $3 \mathrm{C} 17)$. A análise qualitativa dos dados da pesquisa indicou que essas crianças retidas estavam alfabéticas e em níveis iniciais de apropriação da norma ortográfica (conforme o Quadro 1).

\footnotetext{
${ }^{3}$ Para preservar os nomes das crianças utilizamos uma sigla para cada criança. A sigla traz inicialmente a identificação da turma ( $3^{\circ}$ ano); o tipo de organização escolar: (C) Ciclada ou (S) Seriada; e, por fim, um número representando cada criança de acordo com a ordem de chamada.
} 
A atividade de produção de textos indicou que muitas delas avançaram na aprendizagem, indo de uma de uma produção completamente ilegível para a produção de texto legível e com sentido. Ou seja, identifica-se uma desconsideração da escola para com os avanços das crianças em relação aos conhecimentos construídos sobre a produção escrita ao longo do ano. No entanto, de acordo com a professora do $3^{\circ}$ ano da Escola $\mathrm{C}$, as crianças não chegaram ao nível de aprendizagem esperado para o $3^{\circ}$ ano, e a orientação oficial do município é que elas não tivessem progressão escolar. Conforme o trecho a seguir da entrevista, não há indicação na sua fala de que os conhecimentos elaborados pela criança durante todo o ano letivo possam ser considerados para a sua progressão escolar, caso ela não tenha construído todos os saberes esperados.

[...] ao final do $3^{\circ}$ ano devia já tá alfabetizado, lendo os textos, entender o que tá lendo, e ser capaz de escrever e ser entendido. [...] sempre a gente ouve falar: tem três anos para se alfabetizar. Nunca vi nada assim, um registro escrito disso. Mas sempre ouvi da rede. Se não conseguir do $3^{\circ}$ ano ela pode ser retida. Então é, os critérios que utilizei está lendo eficientemente, se não espere mais um tempo para poder passar... Porque é preciso ele ter autonomia de leitura e escrita, e se ele tiver alfabético e não tiver autonomia não passo não. Não... Até porque as turmas de $3^{\mathrm{a}}$ e $4^{\mathrm{a}}$ séries aqui elas dizem: eu não vou alfabetizar ninguém, se o aluno chegar até mim ele vai ter que se virar. Então para evitar essa exclusão dos meninos, a gente dá mais um ano para ele repensar... (Entrevista, Professora do $3^{\circ}$ ano $\mathrm{C}$ ).

Em relação à Escola $S$, no perfil inicial da turma de $3^{\circ}$ ano $S$ já havia três crianças (3S6, $3 \mathrm{~S} 10,3 \mathrm{~S} 19)$ retidas no ano anterior, duas delas reprovadas pela segunda vez no mesmo ano/série escolar, e outras quatro crianças $(3 \mathrm{~S} 4,3 \mathrm{~S} 7,3 \mathrm{~S} 13,3 \mathrm{~S} 22)$ tinham sido aprovadas com ressalvas. No perfil final dessa turma duas crianças foram retidas (3S6, 3S19), e uma aprovada com ressalva (3S13), apesar de todas estarem alfabéticas. Destacamos que muitas destas avançaram na produção textual de uma escrita ilegível para uma escrita com sentido e adequada, apesar de essa escrita apresentar dificuldades quanto à segmentação e correção ortográfica. Segundo a professora 3S, essas crianças, no ano seguinte, participariam de ações desenvolvidas pela referida escola, tais como: acompanhamento mais sistemático por não terem atingido o perfil de saída desejado, inserção de todas as crianças aprovadas com ressalvas em projetos de apoio paralelo às aulas regulares e organização das professoras nas turmas de acordo com as suas afinidades.

A análise dos dados indicou que, nas escolas investigadas, a ausência de progressão escolar é vista, segundo as gestoras, como forma de correção do processo das crianças que não chegaram no patamar esperado. Portanto, a falta de progressão escolar é considerada como um tempo extra para a criança aprender o que não foi aprendido no ano letivo. Apesar disso, as 
gestoras apontam que ao impedir que as crianças avancem na escolaridade, a escola corre o risco de estacionar a criança quanto à construção do conhecimento sobre a escrita alfabética.

Ponderamos, assim, que a não consideração dos avanços das crianças entre o perfil inicial e final do ano letivo, bem como a tomada de decisões quanto à progressão escolar sem considerar a progressão das aprendizagens pelas crianças, pode tornar a escola, no final das contas, mais um dos espaços de "preparação dos melhores" sem ampliar o direito à continuidade do processo de escolarização de todas as crianças (MAINARDES, 2009). Entendemos, portanto, que se a escola não cumprir com a sua função de ensinar, a relação entre a progressão escolar e a progressão das aprendizagens continuará a ser um dilema que perdura no processo de ensino e aprendizagem na alfabetização de crianças, independentemente de o sistema de ensino ser seriado ou organizado em ciclos de aprendizagem, conforme ressalta Cortella (2005).

\section{Considerações finais}

A análise desenvolvida neste artigo, acerca da relação entre avaliação e progressão das aprendizagens na escrita ao final do ciclo de alfabetização, destaca elementos da prática das professoras e das aprendizagens das crianças que não podem ser desconsiderados na relação entre os conhecimentos sobre a escrita, avaliação e progressão no final do ciclo de alfabetização.

Em relação às práticas de alfabetização das professoras do último ano do ciclo de alfabetização, os resultados indicaram que elas promoviam várias situações de ensino com diferentes enfoques, buscando alfabetizar e letrar as crianças apesar de terem dificuldades em conduzir as atividades de leitura e produção textual. Essa dificuldade se acentuava quanto ao trato com a heterogeneidade de aprendizagens nas turmas, já que ao mesmo tempo em que teriam de criar situações específicas para as crianças que ainda estavam em fase inicial de alfabetização, lidavam com crianças alfabetizadas e que precisavam avançar em suas construções sobre a norma ortográfica, a produção textual e a leitura. Apesar disso, encontramos tentativas de organizar as atividades considerando a diversidade de agrupamentos e a busca de um atendimento ajustado aos conhecimentos e dificuldades das crianças.

Quanto a esse aspecto, entendemos que as escolhas didáticas e pedagógicas das professoras configuravam as opções adotadas para alfabetizar as crianças no contexto das escolas seriadas e cicladas. Apesar de se pautarem em orientações oficiais diversas, a análise das práticas indicou que ambas as professoras tinham metodologias semelhantes quanto ao ensino da leitura e da escrita. Sendo assim, foi-nos possível traçar alguns elementos que caracterizavam o "perfil alfabetizador" das mesmas, tais como: estabelecimento de uma rotina 
de atividades como elemento estruturante da prática; uso de recursos diversificados; estabelecimento de objetivos de ensino a cada ano; desenvolvimento de atividades com foco na apropriação, consolidação e sistematização do ensino da escrita; consideração da diversidade de aprendizagens das crianças e, por fim, tentativa de avaliar na perspectiva formativa, independentemente do sistema escolar no qual estavam inseridas (série ou ciclo). Além disso, a forma como agiam com cada criança, a lógica presente por trás de suas decisões, as opções feitas em relação a "o quê e como ensinar" e "quando intervir e avaliar" caracterizavam a sua metodologia e tinham como base as experiências e as discussões teóricas vivenciadas, fazendoas refletir sobre as necessárias adequações e inovações à presente realidade, oscilando entre "o antigo e o improvisado". Esta reflexão demanda do professor uma compreensão diferenciada do que é "ser um alfabetizador", elemento presente nas professoras investigadas.

Ao fazermos uma análise da progressão das aprendizagens das crianças identificamos que nas turmas de $3^{\circ}$ ano todas as crianças avançaram em seus conhecimentos sobre a escrita de palavras e de textos ao longo do ano letivo. Porém, algumas dessas crianças não obtiveram progressão escolar por estarem em fase inicial quanto às competências de produção textual. Em nenhum momento as escolas apontaram a possibilidade de permitir a progressão escolar da criança do $3^{\circ}$ ano que ainda apresentasse dificuldades na produção textual, e de garantir o acompanhamento de suas aprendizagens no ano posterior.

Falta-nos, portanto, discutir alternativas. Contudo, como aponta Fernandes (2009), a escola organizada em ciclos ainda não seria a alternativa ideal, na atual conjuntura, por ser uma escola de contrastes entre a lógica seletiva e a lógica democrática de acesso e construção do conhecimento. Nesse sentido, a escola alfabetizadora que idealizamos precisaria ser analisada em seu conjunto para mudanças estruturais que busquem o cumprimento de sua função social: alfabetizar e letrar em tempo oportuno todas as crianças sem desconsiderar os ritmos de aprendizagens e a diversidade inerente aos conhecimentos das crianças na tarefa de aprender a ler e escrever.

Observamos, por um lado, que a não consideração das aprendizagens das crianças atrelada à falta de progressão escolar, ao final do ciclo de alfabetização, pode limitar o direito à continuidade do processo de alfabetização e escolarização de todas as crianças. Por outro lado, defendemos que a progressão escolar, ao longo do ciclo da alfabetização, e além dele, precisa ser garantida ao lado da realização de avaliações permanentes dos conhecimentos das crianças, para que os professores e demais profissionais das escolas e secretarias de educação possam planejar as intervenções necessárias, bem como a garantia do direito de todos a aprender a ler e escrever. 


\section{Referências}

ALAVARSE, Ocimar Munhoz. Avaliar as avaliações em larga escala: desafios políticos. Educação, [São Paulo], 12 dez. 2013. Disponível em:

https://revistaeducacao.com.br/2013/12/12/avaliar-as-avaliacoes-em-larga-escala-desafiospoliticos/\#: :text=No\%20\%C3\%A2mbito\%20da\%20avalia\%C3\%A7\%C3\%A3o\%20educaci onal,quase $\% 20 \mathrm{um} \% 20 \mathrm{~s} \% \mathrm{C} 3 \%$ A9culo\%20de\%20xist\%C3\%AAncia. Acesso em: 21 nov. 2020.

BARDIN, Laurence. Análise de conteúdo. Lisboa: Edições 70, 2007.

BRASIL. Ministério da Educação e do Desporto. Plano Nacional de Educação: PNE/20142024. Brasília, DF: Ministério da Educação e do Desporto, 2014.

BROOKE, Nigel. A comparação das quatro ondas. Boletim GERES: Estudo Longitudinal da Geração Escolar, n. 4, Belo Horizonte, 2008.

CHARTIER, Anne-Marie. Práticas de leitura e escrita: história e atualidade. Belo Horizonte: Autêntica, 2007.

CORTELLA, M. S. Os conceitos de avaliação em ciclos: Repercussão da política pública voltada para a cidadania. In: ALMEIDA, F. J. De (Org.). Avaliação educacional em debate: experiências no Brasil e na França. São Paulo: Cortez Editora; EDUC, 2005. p. 45-57.

CRUZ, Magna do Carmo Silva. Alfabetizar letrando: alguns desafios do $1^{\mathrm{o}}$ ciclo no ensino fundamental. Recife: Editora Universitária da UFPE, 2008.

FERNANDES, Claudia. Escolaridade em ciclos: desafios para a escola do século XXI. Rio de Janeiro: WAK, 2009.

FERREIRO, Emília; TEBEROSKY, Ana. Psicogênese da língua escrita. Porto Alegre: Artes Médicas, 1999.

FARIA FILHO, Luciano Mendes; VIDAL, Diana Gonçalves. Os tempos e os espaços escolares no processo de institucionalização da escola primária no Brasil. Revista Brasileira de Educação, Rio de Janeiro, n. 14, p. 19-34, maio/ago. 2000.

FREITAS, Luiz Carlos de (org.). Questões de avaliação educacional. Campinas: Komedi, 2003.

INSTITUTO NACIONAL DE ESTUDOS E PESQUISAS ANÍSIO TEIXEIRA (Brasil). Avaliação nacional da alfabetização: relatório 2013-2014: análise dos resultados. Brasília, DF: Instituto Nacional de Estudos e Pesquisas Anísio Teixeira, 2015b. V. 2.

INSTITUTO NACIONAL DE ESTUDOS E PESQUISAS ANÍSIO TEIXEIRA (Brasil). Avaliação nacional da alfabetização: relatório 2013-2014: da concepção à realização. Brasília, DF: Instituto Nacional de Estudos e Pesquisas Anísio Teixeira, 2015a. V. 1. 
LINCH, Jaqueline Picetti. Movimentos de exclusão escolar oculta. 2002. 152 f. Dissertação (Mestrado em Educação) - Universidade Federal do Rio Grande do Sul, Porto Alegre, 2002.

MAINARDES, Jefferson A escola em ciclos: fundamentos e debates. São Paulo: Cortez, 2009.

MORAIS, Artur Gomes (org.) O aprendizado da ortografia. Belo Horizonte: Autêntica, 1999.

MORTATTI, Maria do Rosário Longo. Os sentidos da alfabetização. São Paulo: Editora UNESP, 2000.

SILVA, Janssen Felipe da. Avaliação na perspectiva formativa-reguladora: pressupostos teóricos e práticos. Porto Alegre: Mediação, 2004.

SOARES, Magda. Alfabetização: a questão de métodos. São Paulo: Contexto, 2016. 